\title{
Cuento y refrán en la «Novela del capitán cautivo» de Cervantes: el Honesto y agradable entretenimiento de Francisco Truchado y los Refranes de Hernán Núñez
}

\author{
Alfredo Baras Escolá*
}

\begin{abstract}
Resumen
Hasta la fecha han sido mencionados con frecuencia los orígenes folclóricos de la «Novela del capitán cautivo» interpolada en el Quijote de 1605, pero nunca se ha propuesto ningún modelo unitario y completo del cuento en el que Cervantes pudo haberse basado para ensamblar todos los componentes de esta historia con estructura tripartita. Sin embargo, cierto relato latino de Morlini, vertido al italiano por Straparola y, muy especialmente, la libre traducción de este al castellano por Francisco Truchado, nos ofrecen una secuela del cuento popular de «Los tres hermanos hábiles» coincidente en múltiples detalles precisos con el texto cervantino. Debe destacarse que en 1591 el autor visitó Baeza, patria y lugar de trabajo y de residencia de Truchado, donde había sido publicada la versión de Straparola bajo el título de Segunda parte del Honesto y agradable entretenimiento de damas y galanes (Juan Bautista de Montoya, 1581, 1582, 1583).
\end{abstract}

Palabras clave: cuento folclórico; refrán; Girolamo Morlini; Gianfrancesco Straparola; Francisco Truchado; Hernán Núñez; Baeza.

Title: Folktale and saying in Cervantes' "Captive captain's Novel»: Francisco Truchado's Honesto y agradable entretenimiento and Hernán Núñez's Refranes

\footnotetext{
Abstract

Up to now, folkloric sources of the «Captive captain's novel» in Don Quixote of 1605 have commonly been mentioned, but an unitary full story model that Cervantes could have based

* Instituto Goya de Zaragoza. abaras11@gmail.com / ORCID iD: https://orcid.org/0000-00026913-714X.
} 
on, when assembling all components of this novel constructed in three parts, has never been proposed. However, a certain Latin tale of Morlini, translated into Italian by Straparola and, very specially, the free Spanish version of this by Francisco Truchado offer us a sequel of the folktale «The Three Skillful Brothers» coinciding in many points of detail with the Cervantes' text. It should be noted that in 1591 the author visited Baeza, Truchado's homeland and place of work and residence, where the version of Straparola had been published with the title Second Part of Honest and Pleasant Entertainment of Ladies and Gallants (Juan Bautista de Montoya, 1581, 1582, 1583).

Keywords: Folktale; Saying; Girolamo Morlini; Gianfrancesco Straparola; Francisco Truchado; Hernán Núñez; Baeza.

\section{Cómo citar este artículo / Citation}

Baras Escolá, Alfredo (2018). «Cuento y refrán en la "Novela del capitán cautivo" de Cervantes: el Honesto y agradable entretenimiento de Francisco Truchado y los Refranes de Hernán Núñez», Anales Cervantinos. 50, pp. 137-165, https://doi.org/10.3989/ anacervantinos.2018.005.

Es tan conocida la novela inserta entre los capítulos 37 y 47 del primer Quijote que solo esbozaremos lo esencial del argumento para rastrear su origen en los dos géneros citados. Un padre que ha perdido buena parte de la hacienda por su carácter gastador, adquirido desde que fuera soldado en su juventud, reúne a sus tres hijos: para no acabar derrochando los bienes que aún posee, hará cuatro partes y distribuirá tres entre ellos, quedándose con el resto para mantenerse hasta su muerte. El mayor revela su voluntad de seguir el ejercicio de las armas; el mediano quiere irse a las Indias; el tercero elige la iglesia o acabar sus estudios en Salamanca. A cada hermano corresponden tres mil ducados en metálico, tras vender toda la hacienda a un tío; siguiendo el ejemplo del mayor, que devuelve dos mil ducados a su padre, los otros dos le entregan mil. Todos se separan para seguir su camino. No sabemos si el padre es viudo, circunstancia más que probable porque no se nombra a la madre desde el comienzo hasta la despedida ${ }^{1}$.

Esta historia la refiere el primogénito al cabo de veintidós años, durante los que no ha sabido nada de sus dos hermanos ni de su padre. Cuenta haber embarcado en Alicante con dirección a Génova; en Milán se hace con armas y galas de soldado. Toma parte en la campaña de Flandes, donde llega a ser alférez del capitán Diego de Urbina; lo deja todo para dirigirse a la batalla de Lepanto, «ya hecho capitán de infantería» (I, 39: 232), con tan mala fortuna que es apresado por el Uchalí y conducido a Constantinopla, desde donde participa como remero de la escuadra turca en varias empresas (Navarino, la

1. Aunque la prodigalidad «no le es de ningún provecho al hombre casado y que tiene hijos» (I, 39: 230), los hermanos solo se despiden del padre «y de aquel nuestro tío» (231). De no indicar lo contrario, las citas del Quijote se refieren a la edición prínceps de 1605, modernizando siempre la ortografía. 
Goleta y Túnez). De Constantinopla pasa a Argel después de morir el Uchalí y haber caído en poder del virrey Azán Agá.

Aquí concluye la primera parte de la «Novela del capitán cautivo» y da comienzo la segunda, común en lo esencial a una de las dos historias centrales de la comedia de Los baños de Argel, la de Zara y don Lope, despojada de sus episodios. Estando el soldado preso en Argel, entre los cautivos de rescate, alza la vista y ve que por la ventana de una casa que da al patio asoma una caña con un lienzo atado, que dejan caer cuando él se acerca: contiene cien reales en moneda argelina. Otras cinco veces se repite la esce$\mathrm{na}^{2}$; con la segunda entrega se incluye una carta, donde la benefactora Zoraida, hija del dueño de la casa, Agimorato, revela ser cristiana en secreto y haber elegido al soldado para fugarse con él a España. En otra carta le indica que se rescate y compre una barca; ambos enamorados conciertan encontrarse el día de la huida en el jardín de la costa al que padre e hija se han trasladado para pasar el verano; descubierto por Agimorato el grupo de cristianos prestos a fugarse, deben secuestrarlo y revelarle durante el viaje la situación real de Zoraida, que acompaña al soldado por voluntad propia; tras un frustrado suicidio del padre, a quien abandonan en tierra firme, caen en poder de corsarios franceses, que los despojan de sus pertenencias. Desde la costa de Vélez Málaga se dirigen a la ciudad de Granada, y de allí a la casa paterna del protagonista Ruypérez de Viedma.

Antes de narrar su historia, el soldado y Zoraida han coincidido en la venta con don Quijote y Sancho, el Cura y el Barbero, Cardenio, Luscinda, don Fernando y Dorotea. Concluido el relato, llegan unos desconocidos, que resultan ser uno de los hermanos del soldado, ahora oidor en viaje a Méjico, y su hija; el Cura acaba presentándole a este su hermano mayor y su futura cuñada Zoraida. Se intercalan los amores de doña Clara, hija del oidor, y su enamorado don Luis. Siguen presentes los personajes en varios episodios de la historia central hasta que don Quijote es enjaulado para volverlo a su aldea.

Averiguar la clave de los orígenes de la novela, sucintamente esbozada, requiere centrar la atención en el comienzo del relato autobiográfico (primer tercio del capítulo 39) y en el episodio complementario del reencuentro del soldado y el oidor en la venta (capítulo 42), tanto como en la historia de Zoraida (40-41). Nos servirá el contexto para comprobar hasta qué punto Cervantes es capaz de recrear con libertad una historia desde las fuentes más humildes. Ya que hasta la fecha la crítica apenas se ha interesado en asociar las tres partes del cuento, y los ensayos sobre Zoraida o la relación de la novela con la historia central han dejado en segundo plano la historia familiar del protagonista, cuanto desde ahora señalemos irá marcado forzosamente por el signo de la novedad.

Pero antes conviene exponer otros puntos de vista.

2. El primer lienzo atado contiene diez cianíis, con valor de diez reales cada uno (I, 40: 238); el segundo, cuarenta escudos de oro españoles (238v); el tercero y el cuarto, más de cincuenta escudos, en monedas de oro y plata, y cien de oro (241-241v); el quinto y el sexto, dos mil de oro y mil (242v, 243). 


\section{CUENTOS Y REFRANES TRAS EL FUEGO}

Cervantes ya advertía, por medio del cura, que el relato del padre y sus hijos oído al capitán Viedma, «a no contármelo un hombre tan verdadero como él, lo tuviera por conseja ['cuento popular'] de aquellas que las viejas cuentan el invierno al fuego» (I, 42: 259v); «la conseja que a vuestro parecer le oístes» (260r), como rectifica el oidor, debe entenderse, de acuerdo con ed. Rico (I: 545, n. 26), 'lo que le oísteis, que os pareció que era conseja', sugiriendo un trasfondo real que ahora no podemos analizar.

A Clemencín le recuerdan las palabras del cura las «consejas detrás del fuego» de Celestina, así como los Refranes que dicen las viejas tras el fuego, del marqués de Santillana (ed. Quijote II: 123, n.). Según luego añadiremos, es cierto que en el relato se incluyen dos refranes («Iglesia o mar o casa real», «Más vale migaja de rey que merced de señor») y que, según el cura, el padre dio a los tres hermanos «ciertos consejos mejores que los de Catón» (259v). Refranes y consejas son dos modalidades del género sentencioso asociables por su contenido (Bizzarri 2009) o sus denominaciones (Darbord y Oddo 2008: 66; Oddo 2015: 115-116), y esto desde la Edad Media hasta bien entrado el Siglo de Oro. A tal propósito citaba Chevalier (1999: 37) un texto muy significativo de Sebastián de Horozco: «"Érase que se era”, estas son unas palabras antiguas de que las comadres viejas usaban cuando, juntas a las noches en invierno al fuego, por pasar tiempo se contaban unas a otras cuentos que llamaban consejas». Cervantes mismo vuelve a nombrar «las consejas que en las largas noches del invierno, en la chimenea», contaban las criadas de Leonora («Celoso», Novelas ejemplares, 141v); e identifica «consejas o cuentos de viejas, como aquellos del caballo sin cabeza y de la varilla de virtudes, con que se entretienen al fuego las dilatadas noches del invierno» («Coloquio», 266). Tales relatos aparecían así descritos desde Quintiliano y san Pablo hasta Erasmo de Rotterdam y Vives (Lada 2007: 323-324); en noviembre «las viejas tras el fuego ya dicen las pastrañas», según el Arcipreste de Hita. Sobre el referente de estos y otros ejemplos de CORDE, cuando las mujeres se reunían de noche para hilar, mientras iban desgranando refranes y cuentos en toda Europa, han tratado con acierto Frutos Martínez (1998), Pedrosa (2004: 30-34, 180-182) y Rodríguez Valle $(2012,2013)$. Solo Cervantes logra enlazar con absoluta originalidad cuento y novella (Paredes 1984: 449450).

Aquella vieja sabia en consejas, voz de la experiencia por aplicar verdades generales a casos específicos, será pronto cuestionada como transmisora de falsedades (Ramadori 2013: 9-11). En el diálogo del cura y el oidor se aprecia esta dicotomía. 


\section{EL CUENTO ORAL DE LOS CUATRO HERMANOS HÁBILES}

Schevill y Bonilla ${ }^{3}$ ya adscribieron al cuento popular el relato-marco de la «Novela del cautivo». Asimismo, Casalduero (1970: 168): «El comienzo de la narración está fuertemente arraigado en el cuento, esto es, en la tradición»; y Allen (1976: 150) apreciaba «un sabor casi folclórico». Será Murillo (1975: 93) quien identifique un motivo preciso, la división de la herencia paterna y la separación; añadirá otro más (ed. Quijote I: 472, n. 1 y 1983: 231), el reencuentro de los hermanos en la venta; en conclusión (1983: 229), el relato es un cuento y no una novela, aunque un cuento inserto en un contexto novelístico. Chevalier (1981: 886-887) señalaba algunas divergencias. Rodríguez y Larson (1985: 84 y n. 6) ven «claras» huellas de tres motivos de Thompson, de los que ninguno coincide con el relato 4 . Para Moner (1988: 59), el inicio está calcado del cuento maravilloso y el relato acaba en leyenda, situándose entre ambos la tranche de vie del capitán. Observa Parodi (1991: 434) en la situación inicial, con «motivos y temas del cuento folclórico» sujetos a la «ley de tres», múltiples transgresiones del código. Se trata de avances parciales, porque no se ha encontrado un modelo para las tres partes del cuento en su conjunto; ningún autor especifica con nitidez el motivo central del que ha partido Cervantes ni propone un cuento donde aparezcan reunidos los demás.

Sin embargo, gran cantidad de textos análogos habían sido ya recogidos y estudiados por los folcloristas; entre ellos, uno tan divulgado como «Die vier kunstreichen Brüder» ('Los cuatro hermanos hábiles') de los hermanos Grimm (Ranke 1979: 903-911).

Espinosa (1946-1947) centró su análisis en los cuentos hispanos en que se promete entregar una novia a quien encuentre «La cosa más rara del mundo» (I, 360-364, n. ${ }^{\circ} 150$, y III, 83-89); tres hermanos salen a buscarla. Tres variantes, asturiana, castellana y mejicana, se acercan a nuestro relato: habiendo puesto a prueba un padre las habilidades de sus hijos, los tres rescatan a la princesa (el ladrón la roba, el cazador mata al dragón que la vigila y el sastre remienda la barquilla); acaba casándose con el menor.

Dio un paso más Espinosa hijo (1987: I, 299-300, n. ${ }^{\circ}$ 132) recogiendo un cuento oral muy similar al que sirvió de modelo a Cervantes, sin citar a este en ningún momento, titulado «El ladrón, el sastre, el cazador y el astrónomo».

3. «Entre las narraciones populares y folclóricas de toda Europa se halla el cuento del padre e hijos (suelen ser tres) a quienes aquel despide para que vean el gran mundo y escojan una carrera que emprender. A cada uno le da el padre buenos consejos o su bendición y en algunos cuentos le entrega un anillo o algún talismán para guardarle contra el mal» (Quijote, ed. Schevill y Bonilla, II: 443, n. 203-29).

4. M271: «Los hijos acuerdan reunirse en la tumba de su padre tras haber salido al mundo durante un año para aprender un oficio»; se da en China. N730: «Reunión accidental de familias», muy frecuente, sin más especificaciones. N733: «Encuentro accidental de hermanos», en Irlanda, Islandia y la tradición judía. 
Consta de tres partes: un leñador viudo y muy pobre tiene cuatro hijos, a los que envía a buscar fortuna y que acaban dedicándose a los oficios citados; vueltos al cabo de un año, se divulga que la hija del rey ha sido raptada por un dragón y quien la rescate será su marido: el astrónomo la divisa, el ladrón la libera, el cazador mata al dragón, que cae sobre el barco, y el sastre lo cose; los cuatro superan otra prueba y, ya que todos muestran iguales méritos, ninguno se casa con la princesa. Fue recogido en Roa (Burgos) el 14 de julio de 1936. Una sustanciosa nota (I, 490) aporta bibliografía, sitúa el cuento en España y Portugal, América, Cabo Verde y Filipinas ${ }^{5}$, y lo identifica con el n. ${ }^{\circ} 653$ de Aarne-Thompson (1961) — como su padre a partir de la edición de 1928 - y con 17 motivos de Thompson (1955-1958), de los que interesan dos, ubicados en Italia: F660.1: «Hermanos adquieren extraordinaria destreza. Vuelven a casa y son puestos a prueba» (alusivo a tipos 653 «Los cuatro hermanos hábiles», 654 «Los tres hermanos», 1525); y R166: «Hermanos con extraordinaria destreza rescatan princesa».

Reiteran el tipo ATU 653 Rodríguez Almodóvar (1982: 141-144, 195-198, 229), con un nuevo cuento sevillano; Camarena (1991: I, 266-275 y nota 116117 , p. 430), con otras dos versiones orales leonesas; y Camarena y Chevalier (1995: 662-670). Todos siguen ampliando las referencias bibliográficas.

Ningún autor relaciona estos cuentos orales con la novela del capitán cautivo. Dejamos para más adelante el modelo de «La hija del diablo» sugerido por Chevalier.

Resaltaremos por ahora las analogías de fondo. En el Quijote observamos las tres partes constitutivas del cuento referido: a) los hermanos, tras salir de la casa paterna, se separan en busca de un oficio que acaban dominando; b) uno de ellos logra rescatar a una joven en otro país; c) anuncia su deseo de casarse con la joven rescatada, antes de volver a casa. Cervantes respeta la estructura simétrica, haciendo notar sus deudas. Pero no todo son coincidencias: en un relato con idéntico grado de realismo que la historia central donde se integra, no tienen cabida los componentes maravillosos (Pedrosa 2004: 223).

Pese a las similitudes, algo más que considerables, descartamos estos posibles modelos de Cervantes por razones que en su lugar expondremos. Al no conocer versiones orales del cuento en el Siglo de Oro, será forzoso interesarnos de momento por las posibles fuentes escritas y cultas con igual origen folclórico.

5. Con versiones hispánicas en Asturias, León, Castilla, Andalucía y Cataluña; en Santo Domingo, Puerto Rico, Méjico, Estados Unidos y Chile; no olvida citar el cuento n. ${ }^{\circ} 129$ de los hermanos Grimm («Los cuatro hermanos ingeniosos»). Sobre los cuentos filipinos, véase Fansler (1921: 116-118, 133-135). 


\section{LAS VERSIONES CULTAS DE MORLINI, STRAPAROLA Y TRUCHADO}

Acerca de las Novelas ejemplares Pierre Darnis (2013: 12) ha planteado la tesis de que su autor creó la novela corta basándose en el folclore maravilloso, no menos que en algunos novellieri y «en el taller de escritura de Straparola, también nutrido por las consejas viejas» o cuentos populares; y trae a colación las palabras del cura antes citadas. Pues si bien las novelle de Straparola, Masuccio y Bandello fueron publicadas entre 1476 y 1573, las ediciones en lengua española se concentran entre 1580 y 1603 (9) ${ }^{6}$. No debe olvidarse que la «Novela del capitán cautivo» quizá fuera en su origen una novela ejemplar más tarde incluida en el Quijote y parangonable con las doce de 1613.

Con tales precedentes estábamos en condiciones de rastrear la fuente directa de Cervantes. Y gracias a un ensayo de Marcos Ruiz Sánchez (2014), este ha sido el feliz hallazgo. Entre los cuentos de Girolamo Morlini, publicados en latín con el título de Morlini Novellae (Nápoles, 1520), el n. ${ }^{\circ}$ LXXX «De fratribus qui per orbem pererrando ditati sunt» («Los hermanos que se enriquecieron recorriendo la tierra») —editado y traducido por Ruiz Sánchez - ofrece muy significativas coincidencias con Cervantes. Tres hijos de un hombre pobre, tras despedirse de su padre, se separan en una encrucijada para buscar su camino: acabarán ganándose la vida como soldado (el mayor), constructor de barcos (el mediano) y adivinador (el pequeño). Los tres destacan en sus respectivas ocupaciones. Aquel, sirviendo a un capitán, se convierte en el soldado más valiente, y es capaz de escalar una pared sirviéndose de dos puñales; el mediano progresa tanto que es conocido como el mejor naviero de la región; el pequeño aprende el lenguaje de los pájaros. Habían quedado de acuerdo en reunirse al cabo de diez años. Cuando los tres están comiendo en una taberna, una urraca les revela la existencia de un inmenso tesoro; el más joven interpreta los graznidos, de suerte que pueden volver ricos a casa de su padre. Otra ave les hace saber que en el mar Egeo, y en la isla de Quíos, la hija de Apolo había encerrado a Aglae con todos sus tesoros en una fortaleza guardada por una serpiente que vomitaba veneno y fuego y por un basilisco; quien la rescatara obtendría su mano y sus riquezas. Construida una veloz nave por el segundo hermano, el primero, con dos puñales, logra escalar la torre, baja a Aglae mediante una cuerda y arroja desde arriba joyas y gran cantidad de oro. Surge la duda de quién merece a la doncella, pues los tres han colaborado en el rescate. De tal forma queda en el aire el desenlace.

6. En realidad, desde 1578, fecha de la prínceps del Honesto y agradable entretenimiento de Francisco Truchado - del que luego nos ocuparemos-, a raíz del hallazgo de González Ramírez (2011b) y Coppola (2013). Darnis reproduce datos sin actualizar del primero de ambos críticos (González Ramírez 2011a: 1235). 
Observamos tres partes. Para empezar, el triunfo de los hermanos resolviendo la carencia inicial; como segunda parte se incluye a Aglae, «la princesa rescatada» de Ruiz Sánchez, que no advierte la adaptación del cuento en el Quijote; por fin, el regreso a casa.

Cervantes añade al primer tercio del cuento una segunda historia - que se diría heterogénea - sobre Zoraida, hija de Agimorato, seguida del tercio complementario acerca del reencuentro familiar. Sin embargo, la historia de amor en Argel parece tan imprescindible como el cuento marco: se repite la estructura tripartita del cuento de los tres hermanos con igual contenido. Adelantar una hipótesis sobre la cronología resulta complejo. Buena parte de la crítica opina que la novela intercalada fue compuesta mucho antes que el resto del Quijote; en un segundo momento es probable que Cervantes ideara el argumento de Zara y don Lope, en la Comedia de los baños de Argel, sobre la base del viejo relato inédito; por fin, incluiría la historia breve en la novela ${ }^{7}$. En todo caso, desconocemos qué debía la comedia a la novela corta, en qué consistía el original y qué partes de la historia de Zoraida fueron suprimidas, alteradas o añadidas para adaptarlas al motivo del rescate de la princesa y conformar la historia tal como nos ha llegado.

Al elaborar su relato, Cervantes no pudo conocer la rarísima edición latina de Morlini, que acabaría siendo prohibida. Ruiz Sánchez (2014: 6) comenta que Giovan Francesco Straparola adaptó la novella en su noche VII, cuento 5 de Le piacevoli notti (Venecia, 1550, 1553). En verdad apenas hizo Straparola sino traducir al italiano el cuento de Morlini casi al pie de la letra (ed. Beecher, II: 129). Hay versión castellana del italiano, esta vez con modificaciones, a cargo del baezano Francisco Truchado, titulada Honesto y agradable entretenimiento de damas y galanes (Zaragoza, Juan Soler, 1578), hasta la sexta noche, y una Segunda parte... (Baeza, Juan Bautista de Montoya, 1581), desde la séptima hasta la duodécima. González Ramírez (2011a: 1234-1235, 2011b) da cuenta de la extraordinaria fortuna editorial de esta versión entre 1578 y 1598; Marco Federici (2011) y Leonardo Coppola (2016) se han ocupado de editar las dos partes. Corresponde el cuento que nos ocupa, editado en la Segunda parte..., a la noche IX, fábula 3 de Truchado ${ }^{8}$. Ya que esta versión no difiere en lo esencial de Straparola, Cervantes pudo basarse en ella, en el original italiano o en ambos. En lo único que difieren de Cervantes las tres versiones es que en ninguna divide el padre la herencia; son los hijos quienes le solicitan buscar su vida. Otros cuentos, populares o cultos (ATU 654), incluyen esta variante.

Podrían agregarse docenas de textos orales protagonizados por tres hermanos que salen del hogar paterno en busca de oficio. Nos interesa, sin embargo, acotar el cuento como totalidad: deben aparecer un soldado, un navegante y un sabio; es liberada una doncella; el soldado rescatador quiere desposarla; y

7. Baras Escolá, ed. «Los baños de Argel», en Comedias y tragedias, II: 87-88.

8. Con el título «Tres hermanos pobres peregrinando por el mundo- mediante su buena ventura e industria se hacen ricos», ed. Coppola, 396; salvo indicación contraria, citaremos esta edición. 
este desenlace queda abierto. Descartaremos los cuentos sin tales formantes. Enumerando todos aquellos en que simplemente aparecen tres hermanos perderíamos el hilo conductor entre una selva de ejemplos que nada aportarían a nuestra propuesta.

Quien se interese por la génesis completa, las ramificaciones y variantes de «The contending lovers» puede consultar a Farnham (1920). Desde su origen sánscrito, persa y árabe hasta las versiones europeas del tema aparecen cinco tipos: en el segundo, tres personajes hábiles (sabio, viajero, soldado) rescatan en un barco a la princesa $(275,284-287)$; solo en Morlini hay coincidencias con la novela del capitán cautivo.

Advertíamos que Cervantes omite los componentes maravillosos conservados por Morlini, Straparola y Truchado. Frente a los cuentos orales, veamos las coincidencias de estos textos y el cervantino, algunas de cuyas variantes no dejan de ofrecer analogías.

\section{Los tres hermanos hábiles y sus oficios}

En Cervantes encontramos a tres hermanos (y no cuatro o más, como en la mayor parte de los cuentos orales de este tipo), que eligen desde un principio los oficios de soldado (el mayor), comerciante (el mediano) y estudiante (el menor). Tanto sus habilidades como el orden de elección apenas difieren del cuento de Morlini y de las versiones de Straparola y Truchado: soldado, navegante (que sugiere el comercio) y estudioso del lenguaje de los pájaros; como indicaba Farnham (1920: 275, 297-298), desde las versiones sánscritas el núcleo de personajes está formado por «a man of knowledge, a fast traveller and a man of war», con múltiples variantes en que se reconoce fácilmente el modelo primitivo. En las versiones orales veíamos cuatro profesiones tan dispares como ladrón, sastre, cazador o calderero y astrónomo. Aunque la forma de hacer fortuna sea muy otra en los textos cultos, también logran destacar los tres hermanos cervantinos en su profesión: el militar como capitán de infantería con posibilidades «de ser presto maestre de campo» (Quijote I, 42: 259v), con rango no inferior sino al de general (ed. Rico I: 544, n. 22); el mediano se hace rico en el Perú, y el pequeño acaba de ser proveído como oidor en la Audiencia de Méjico. Ruypérez se enriquece con el tesoro de Zoraida (equiparable a la princesa del cuento), aunque durante el viaje de vuelta a España el renegado arroje al mar un cofrecillo repleto de escudos de oro y Zoraida sea despojada de sus joyas (I, 41: 253v); el indiano, «con lo que ha enviado a mi padre y a mí ha satisfecho bien la parte que él se llevó», repartiendo sus riquezas, nos cuenta el hermano pequeño (I, 42: 260). Como dirá al oidor el cura, al capitán y a su futura esposa los corsarios «los pusieron en la estrecheza que veis, para que vos mostréis la liberalidad de vuestro buen pecho» (I, 42: 261). 


\section{El reencuentro familiar}

Mientras que en los cuentos populares y artísticos se reúnen los hermanos antes de serles propuesto el rescate de la princesa, en que todos intervienen, Ruypérez ya ha liberado sin ayuda alguna a su benefactora; será después cuando se encuentren ambos con el oidor. Al despedirse de sus dos hermanos no fijan ni dónde ni cuándo reunirse, a diferencia del cuento oral, en que acuerdan reencontrarse al cabo de uno, dos, cuatro o más años en el mismo cruce de caminos donde se separan; en Morlini, Straparola y Truchado el plazo es de diez años. Por azar, frente a los textos precedentes, coinciden dos hermanos cervantinos, al cabo de veintidós años, en una venta donde se alojan y cenan. En los cuentos artísticos — no así en los populares - se encuentran los dos hermanos mayores y han de esperar al tercero. Tal vez por eso Cervantes yerra, haciendo decir al oidor: «Otro hermano menor mío», «Mi menor hermano está en el Pirú» (Quijote I, 42: 260), habiendo sido presentado aquel como el «segundo hermano» (39: 231) ${ }^{9}$. De cualquier modo, el reencuentro de los hijos con el padre - a mitad de la historia en el cuento oral, una vez hallado el tesoro oculto cuya existencia les hace saber un ave, y en los tres autores cumplido entonces y supuesto al final de la historia, cuando regresan a su «patria» (esto es, a 'la tierra paterna') - es aplazado por el novelista hasta después del fin de la historia; como veremos analizando el desenlace, en las versiones folclóricas los hermanos se dirigen al palacio del padre de la princesa con el fin de entregarle a su hija y solicitar su mano (en simetría con la escena en que habían prometido devolvérsela); no se alude a una vuelta a la casa del padre: es más, ni siquiera se menciona al personaje.

\section{La joven rescatada en una isla}

Si en los cuentos anónimos la princesa está cautiva en un reino sin identificar, los tres autores ambientan el relato en Grecia. Cervantes parece una voz discordante. Con todo, siendo cierto que Chios (Morlini), Chio/Chiò (Straparola) o Chio (Truchado) — donde está cautiva Aglae - se identifica con la isla Quíos del Egeo ${ }^{10}$, esta pertenecía al imperio turco desde 1566; y Argel, donde vive Zoraida, era gobernada por un virrey al servicio de la dinastía otomana ${ }^{11}$. En su edición de Truchado (III: 158, n. 997) recuerda Fe-

9. No acaban de convencer las razones de ed. Rico I: 545, n. 27: «El segundo, que eligió marchar a las Indias, en relación al mayor hermano, es decir, al cautivo» (cursiva del editor).

10. Straparola, 39v: «Nel mare Egeo pel circoito di circa dieci miglia u'è una Isola che si chiama Chio», «con buon uento trauersando il mare s'inuiarono uerso l'isola di chiò». Citamos siempre la edición de 1567.

11. Barbarroja, nacido en la cercana Lesbos y sultán de Argel en 1516, sería gobernador del norte de África y de Rodas, Eubea y Quíos. Argel y Quíos se contaban entre los principales mercados de cautivos. 
derici que, designando el topónimo español Chio, en contra del italiano, la isla de Íos, una de las Cícladas, quizá el traductor no yerra sino que pretende ser fiel al texto original. Morlini y Straparola se refieren inequívocamente a Quíos, y en el castellano de la época Chio podía referir a Quíos ${ }^{12}$. De todas formas, Íos también había sido anexionada por los turcos en 1537. Junto al deseo de actualizar el cuento hay en Cervantes una ubicación análoga a la que ofrecen sus historias bizantinas de cautiverio trasladadas a Argel. Y no se olvide que esta era llamada en árabe Algezeir ('la isla' o 'la ciudad de la isla') por estar «muy cerca de aquella isla pequeña que dijimos, que solo un tiro de ballesta dista della» (Haedo, Topografía 3).

Los cuentos populares nombran a una princesa, hija de rey, no así las versiones cultas: Morlini da su nombre, Straparola la llama «donna» (39v) y Truchado «dama» y «ninfa» (398). Por más que Zoraida se muestre «ataviada como una reina» o «hija de príncipes» (Márquez 1975: 121) y superpongamos al personaje su «modelo real», de acuerdo con Oliver Asín (1947-1948) — la hija de Agimorato, viuda del sultán de Marruecos y casada con Hazán Bajá, rey de Argel—, Cervantes no la considera princesa.

\section{El nombre de la joven}

Aglaea (Morlini) o Aglea (Straparola, Truchado), nombre común a la cautiva y a una de las tres Gracias (Aglae, Aglaya), significa 'resplandeciente, luminosa'"13; acaso como Zoraida, cuya etimología de Turayyā ('tipo de lámpara' y la brillante constelación de 'las Pléyades') analiza en profundidad Montaner (2006: 255-265). Turayyā dio Çoraya/Zoraya, pero en el trabajo citado se deslizan dos errores graves. Lejos de poderse afirmar «que Zoraida no existía en su momento como antropónimo fuera del texto del Quijote» (261), ya aparece mucho antes, al menos en veinte citas literarias, comprobadas en los originales y en facsímiles. Así, en cuatro romances moriscos (ocho casos) del Romancero General de 1600, impresos antes en sendas Flores de romances entre 1592 y 1597, junto con otros dos de Gabriel Lobo Lasso de la Vega en su Manojuelo (1601) ${ }^{14}$. En las Guerras de Malta (1599), con aprobación de 1596, Diego de Santisteban ofrece seis menciones de Zorayda /

12. En CORDE varios autores de los siglos XV-XVI asocian Chio con el vino (Alfonso de Palencia), el lentisco (fray Vicente de Burgos) o el mito de Ariadna, localizados en Quíos y no en Íos.

13. Aglaia o Aglaya se asocia a 'luz y esplendor' o 'resplandeciente' en Fernando de Herrera (1580); y a 'resplandor' en Pérez de Moya (1585), Juan de Pineda (1589) y Diego López (1615), según CORDE. Véase Straparola, 2012, The Pleasant Nights, ed. Beecher, II, 128.

14. CORDE registra dos citas del nombre en Lobo Lasso de la Vega (1601) y doce en el Romancero, errando por citar ed. Durán (I, n. $\left.{ }^{\circ} 170,187,188,190,191,239\right)$, seguido también por Silveira (1980: 176). En realidad, la editio princeps de 1600 lee Zayda por Zorayda en tres casos (ff. 276v-277, n. ${ }^{\circ} 188$ de Durán), y en otro, çorayça (ff. 157-157v, n. 239 de Durán), coincidiendo en el resto (ff. 90 , 270v, 306, 350-350v); ya aparecían iguales lecturas del texto en los facsímiles de Flor cuarta de 1592 (Zorayda, «En un alegre jardín»), Flor séptima de 1595 (Zoraida, «En la más terrible noche»), Flor 
Zoraida $^{15}$. En cuanto a santa María de Alcira, antes Zoraida (vuelta cristiana en el s. XII), entre la historia y la leyenda hagiográfica, es nombrada así desde el Libro de la vida ... de S. Bernardo (1600), de fray Honorato Gilbau, con cuatro citas tomadas de fuentes orales moriscas, según el autor ${ }^{16}$; también la Zorayda cervantina se llamará María (Quijote, I, 37: 224v-225 y 40, 241). Dado que el nombre estuvo de moda en los años noventa del siglo XVI, aquí tenemos un dato esencial para fechar el relato, abonando a quienes lo juzgan la parte más temprana del Quijote. Si la Zoraida/María cervantina se basa en la Zoraida/María de Gilbau, esta versión sería posterior a 1600.

Tampoco es Zoraida nombre forjado artificialmente por el narrador cruzando Turayyā, Zuhayrah y Zaida (no cualquiera de las así llamadas, sino la amante mora de Alfonso VI de Castilla), según da a entender Montaner, sino antropónimo registrado en documentos hispanos. Pese a la escasez de nombres femeninos musulmanes en textos legales y a la prohibición de portar nombres árabes desde la conversión forzosa de 1502, entre los siglos XIV y XVI nos salen al paso cuatro mujeres hispanoárabes portadoras del nombre Zoraida en tierras de Albacete, Murcia, Campo de Calatrava o Almería ${ }^{17}$; esta vez no ha sido posible consultar ningún original. Cervantes parece haber actualizado literariamente en la lectura romanceril Zorayda (77 veces en Quijote, una Zoraida) la de los nombres Zohra ('lucero del alba') o Zoraya, de los que

octava de 1596 (tres Zorayda, «Ya por el balcón de oriente») y Flor novena de 1597 (tres Zorayda, «Denme el caballo de entrada»), según Rodríguez-Moñino (1957, 1973-1978: II).

15. Zorayda, Parte I, Canto 5, ff. 49v y Tabla, [300]r-v, dos veces; Zoraida, ff. 52r dos veces y $55 \mathrm{r}$.

16. Zaida y Zoraida, hermanas de san Bernardo de Alcira, fueron muertas y sepultadas con él en esta ciudad el 21 de agosto de 1181; descubiertos sus restos en julio de 1599, se trasladaron en 1603 a Poblet (Carrasco Urgoiti 1996: 203) y después quedaron repartidos entre Carlet, Valencia y Alcira. Montaner (2006: 261, n. 59) considera que los nombres de ambas santas no aparecen hasta la hagiografía de san Bernardo por Castillo Solórzano, Patrón de Alcira (1636), 176-177: «Zayda se llama ya Gracia, / Zorayda en María se trueca / el nombre»; y sugiere que Zoraida sea préstamo cervantino; pero ya Gilbau daba cuatro menciones: «Los nombres de las hermanas gloriosas, con los cuales se nombraban siendo moras, he sabido por informaciones de algunos nuevos convertidos que me dijeron haber oído decir se llamaban Zayda y Zorayda (y aun dice fue este último el de la madre destos santos)» (Libro, «Prólogo al lector»); los padres de Almanzor y Amete tenían dos hijas, «la una Zayda, y la otra Zorayda» (11); «llamadas Zayda y Zorayda» (95). Gilbau no asocia cada nombre árabe con el correspondiente cristiano, pero el orden siempre es el mismo: el ya citado para los primeros, y Gracia y María en tres ocasiones $(102,135,136)$. Castillo Solórzano, de origen valenciano, sigue a Gilbau, sin influencia alguna de Cervantes. Ya en 1611 Escolano (cols. 910, 918), en 1613 Diago (267r) y en 1618 Bleda $(822,824)$ revelan esta fuente al consignar que «Zayda y Zorayda» se bautizaron con los nombres de «Gracia y María». Aunque citas posteriores asocien a Zoraida con Gracia, de haber coincidido Cervantes habría vuelto a referir a la Gracia Aglea.

17. Mose Cohen de Lorca compró en Hellín «una esclava mora, Zorayda, para su hija» en 1373, en realidad una cristiana llamada Catalina, que había vivido en Écija (Torres 1985: 104-106). En la Arrixaca de Murcia se avecinda el 29 de noviembre de 1466 el moro «Cad, hijo de Ahmed, con Zorayda su esposa y Muhammad su hijo» (Torres 1977: 94, n. 14). Entre los bautizados el 27 de abril de 1502 en Villarrubia de los Ojos (Ciudad Real) se encontraba Zoraida, esclava de Hamete, desde entonces Catalina (Gómez Vozmediano 2000: 32, 204; Dadson 2007: 55, 801). Zoraida, de Albánchez (Almería), con un niño de pecho, era esclava del sedero Pedro Sánchez, ya fallecido en 1580 (Guerrero 2007: 42). 
acaso retuvo la extraordinaria hermosura asociada a las Pléyades o al planeta Venus: Isabel de Solís se había convertido en Zoraya para unirse al rey Muley Hasán de Granada (Szpiech 2017) ${ }^{18}$. También la Virgen María es stella matutina en las letanías, de suerte que Zoraida-María coincidirían en igual significado. Entre las advocaciones de Fátima, hija predilecta de Mahoma, destaca Zahra ('estrella resplandeciente') 19; Zoraida remite con la misma nitidez de Zara en Baños a Morlini. En versiones populares, la princesa rescatada suele carecer de nombre o no guarda relación con el de Aglaea, que Cervantes traduce Zoraida.

\section{El rescate}

Zoraida no es vigilada por una serpiente y un basilisco ni por un demonio, un mago o un rey (Farnham 1920: 275), pero se muestra desde lo alto a Ruypérez como Aglae en su torre. Luego comprobaremos si cabe identificar a sus guardianes bajo el aspecto realista de Agimorato. En su primera carta, la mora rogaba al capitán ocultar su plan de fuga, «porque si mi padre lo sabe, me echará luego en un pozo y me cubrirá de piedras» (I, 40: 239v); lo describe como un «moro furibundo y capaz de cualquier cosa» (Márquez 1975: 119), pese a la ternura mostrada en la escena del jardín y su afabilidad con los cristianos, y en coincidencia con la futura maldición a su hija durante la huida.

En los cuentos orales no se indica cómo rescata el soldado a la cautiva. Morlini $(3,5)$ la hace descender «atada con una cuerda» (reste); en Straparola (39v), «legatala con una corda»; en Truchado (398), la «descolgó»; en los tres autores, después de la cautiva desciende el tesoro. Es Zoraida en Cervantes quien deja caer al suelo, desde el primer momento y en varias ocasiones, «un lienzo atado» a una caña con dinero, joyas y a veces una carta, indicando al capitán que la respuesta también deberá atarla a la caña con «un hilo» (Quijote I, 40: 237v, 240, 241r-v). Será después cuando baje por su propio

18. Mármol Carvajal (Historia 14) evoca a la renegada «Zoraya (no porque fuese este su nombre propio, sino por ser muy hermosa la comparaban a la estrella del alba, llamada Zoraya)»; Lafuente (1859: 176, n. a) apunta que Zoraya 'lucero de la mañana, Venus' (según los cronistas castellanos) significa, en realidad, 'Pléyades', sin referir a ninguna estrella concreta, aplicado a una mujer como símbolo de belleza. En los romances citados son comunes «Zoraida bella» o «la bella Zoraida», y expresiones análogas en Quijote, cuyo número hace pensar en una fórmula (véase n. 19); quizá sugiera Cervantes en una ocasión la hermosura de Venus, el lucero del alba: «Me parecía que tenía delante de mí una deidad del cielo, venida a la tierra para mi gusto y para mi remedio» (245v); es cierto que «nos había parecido la estrella de la caña» (I, 40:238v) y «tornó a parecer nuestra estrella con la blanca bandera de paz del atadillo» (241) no hacen referencia directa a Zoraida - como apunta Montaner (259)_, pero sí en forma de metonimia.

19. Schimmel (1989: 36, 44) también menciona $a z$-Zahrā 'la radiante' como epíteto de Fátima; en Labarta (1987: 53), al-Zahrā' 'resplandeciente' se asocia con Zara/Zahara y con Zuhra 'Venus', por derivar de la raíz \{zhr\}. Salazar de Mendoza (Crónica I: 242) no es el único en llamar a doña Isabel «Fátima la Zoraya». 
pie a embarcarse y salir de Argel, tras haberse mostrado aguardando a los cristianos «a una ventana» del jardín de Agimorato (I, 41: 248).

\section{El desenlace abierto}

Tanto en los cuentos orales como en los artísticos y Cervantes, el protagonista saca de su encierro a la doncella y se embarca con ella para tornar a su país. Es rescatada la doncella en un barco por los tres hermanos, de acuerdo con todas las muestras del subtipo en el cuento; Ruypérez compra una barca, y tanto los preparativos como la huida se amplían (I, 40-41: 241v-257). En el desenlace de las versiones latina, italiana y castellana ya no vuelve a aparecer el rey, padre de la princesa; en los textos populares españoles los tres hermanos devuelven la hija a su padre. Todos los cuentos muestran una disputa entre los rescatadores acerca de su derecho a la mano de la princesa, pues los tres han puesto en juego sus habilidades. Morlini, Straparola y Truchado dejan al lector la sentencia de este litigio judicial, todavía pendiente. Pero en los cuentos orales decide el rey que, siendo iguales sus méritos, ningún hermano puede casarse con la princesa; o es entregada al menor, a veces tras elegirlo aquella. Cervantes muestra su originalidad anunciando las bodas del capitán y de Zoraida, pues nadie más ha participado en el rescate. Con todo, no falta un aspecto problemático a la historia, cuyo desenlace se nos antoja tan abierto como en los cuentos artísticos. «Los lectores tienen derecho a inquietarse por el futuro, difícilmente imaginable, de aquella anómala pareja», ya desde Argel «sumida en un mar de contrastes de todo orden», y más aún en la España coetánea, advirtió Márquez (1975: 121-122): «El futuro conyugal de los protagonistas es, desde el punto de vista crítico, cuestión bizantina», y la historia «no termina, ni feliz ni infelizmente, a pesar de la anagnórisis archiconvencional del hermano oidor» (cursiva del autor). Chevalier (1983: 411) se adhiere a tan sagaz conclusión.

A pesar de que el cuento de Morlini, Straparola y Truchado sea aparentemente uno y el mismo, varios puntos de la versión castellana, ausentes de la latina y la italiana, se ajustan mejor a la historia de Cervantes:

1. En Quijote el soldado y el oidor coinciden en la venta de Palomeque. A los tres los reúne Morlini «in taberna» (Ruiz Sánchez 2014: 2); «nell’hosteria» 'en la taberna', Straparola (39); y Truchado, en «una venta» (397).

2. «Muchos cristianos he visto por esta ventana, y ninguno me ha parecido caballero sino tú. Yo soy muy hermosa y muchacha, y tengo muchos dineros que llevar conmigo. Mira tú si puedes hacer cómo nos vamos, y serás allá mi marido», escribe Zoraida en su primera carta (Quijote I, 40: 239v); esperaba salir de Argel desde la muerte de su nodriza. En Truchado el soldado quiere sacar a Aglea «del infelice encantamiento donde tantos años ha 
vive», y ella confiesa estar «encantada muchos años ha, aguardando esta dichosa aventura» (398). No hay tales alusiones en Morlini o Straparola.

3. Zoraida era «la más hermosa mujer de la Berbería» (Quijote I, 40: 241); su padre la considera «la más hermosa de todo este reino» $(41: 246)^{20}$. Se acumulan en Truchado parecidos calificativos y un superlativo relativo sobre la bellísima Aglea ${ }^{21}$; Straparola suple la falta de referencias en Morlini, limitándose a describirla como «una delle piu gratiate donne che sia al mondo» (39v).

4. «Agi Morato, riquísimo por todo estremo», tenía «una sola hija, heredera de toda su hacienda» (Quijote I, 40: 241) y guardiana de las llaves (242v), quien asegura que «bien habrá para que todos quedéis ricos y contentos» (41: 248v). Según Aglea, el soldado y ella serán «en extremo dichosos y gozaremos de todo este tesoro que aquí verás. / Y abrió una puerta de un aposento, donde le mostró grande número de dineros, perlas y preciosas joyas» (398), de suerte que pronto arribaron a su patria «ricos y dichosos». Nada similar hallamos en Morlini o en Straparola ${ }^{22}$. Adornan a Zoraida «ricas perlas y aljófar», oro y diamantes (I, 41: 245); Truchado llama la torre «el diamante» (398).

5. Don Quijote hace la guardia nocturna para disuadir a los «codiciosos del gran tesoro de hermosura que en aquel castillo se encerraba» (I, 42: 261v), volviendo a evocar el cuento - el tesoro anteriormente oculto en una venta o el «riquísimo y grande tesoro» del castillo (398) - ; véanse puntos 1 y 3.

6. Al salir del jardín, Zoraida «volvía cargada con un cofrecillo lleno de escudos de oro, tantos, que apenas lo podía sustentar» $(248 \mathrm{v})$, descrito como «el cofrecillo donde ella solía tener sus joyas» o «aquel cofre» (250v); más tarde el renegado «tomó el cofre de las riquezas de Zoraida y dio con él en la mar» (253). En Truchado, el liberador de Aglea «en unos cofres echó todo el tesoro» (398); faltan en las versiones latina e italiana.

20. Análogas expresiones hacen pensar en una fórmula encarecedora: «Descubrió un rostro tan hermoso, que Dorotea la tuvo por más hermosa que a Luscinda, y Luscinda por más hermosa que a Dorotea», «la hermosa mora» (I, 37: 224v); «Yo soy muy hermosa» (40: 239v); «la hermosa Zoraida» (243); «la bella Zoraida» (41: 244v); «la mucha hermosura, la gentileza», «su hermosísimo cuello», «Si con todo este adorno podía venir entonces hermosa», «en todo estremo hermosa, o a lo menos a mí me pareció serlo la más que hasta entonces había visto» (245); «la hermosa y bella Zoraida» (247); «la hermosísima Zoraida» (247v, 254), «la bellísima Zoraida» (248); «admirábanse de la hermosura de Zoraida, la cual en aquel instante y sazón estaba en su punto» (256); «Zoraida hermosa» (42: 260v).

21. Es «la más linda dama que hoy se puede hallar en el mundo», «la hermosísima Aglea», «la hermosa dama que buscaba»; «la hermosa Aglea», por dos veces (398).

22. Morlini: «Hic Aglaea cum omni quem aceruauerat thesaurum (aeruscauerat pecuniam ad infinitum numerum, ascendens)», «proiectis carbunculis, gemmis ac cumulo auri, uacuam turrim derelinquens»; es decir: «Aquí permanece encerrada Aglae con todo el tesoro que había acumulado (al subir había acumulado una infinita cantidad de riquezas) [mejor, de dinero]», «tras arrojar desde arriba carbunclos, gemas y gran cantidad de oro, dejando totalmente vacía la torre» (Ruiz Sánchez 2014: 3, 5). Straparola: «è rinchiusa con tutto il tesoro che l'ha ragunato, \& havvi raccolto infinita quantità di danari», «tratti i rubbini, \& gioie, \& un monte d'oro che v'era» (39v). No se mencionan perlas ni diamantes. 
7. En Truchado los guardianes están dormidos; el soldado descuelga a Aglea «secretamente y sin rumor, sin ser sentido de las atroces y vigilantes serpientes» (398), que el narrador latino y el italiano parecen haber olvidado. Quizá no sea exacto identificar con estos guardianes a Agimorato, pero el padre de Zoraida también duerme en el jardín (I, 41:248v); al ir a despertarlo el renegado, la mora pide a todos «que nos estuviésemos quedos, sin hacer ningún ruido» mientras vuelve con el cofre; pese a todo, cambia el argumento haciendo que Agimorato «despertase en el ínterin y sintiese el ruido».

8. La joven se ofrece como esposa, facilita su rescate y muestra sus riquezas en Truchado y Cervantes; no es liberada de forma pasiva, como en Morlini y Straparola.

9. Es más, tan solo en Truchado y Cervantes la joven entabla diálogo con su rescatador - muy desarrollado en Cervantes, por carta y en el jardín-, mientras que en Morlini y Straparola guarda silencio hasta el desenlace.

Llegados a este punto, convendrá revisar la hipótesis de Chevalier (1983), que situaba el origen del relato cervantino en el cuento folclórico de «La hija del diablo»; Pedrosa (2004: 143) reitera supuestas fuentes orales. Un joven cae en poder del diablo (variante del ogro o gigante); la hija del captor, con sus artes mágicas, ayuda al prisionero a realizar las tareas difíciles impuestas y, cuando huye con él, recibe la maldición paterna. Salvo el último punto, están ausentes los demás: Agi Morato no puede identificarse con el diablo, tampoco es el amo del capitán y faltan las empresas del cuento. Hay un argumento más para desestimar la propuesta. Confiamos en haber probado el origen del conjunto de la historia de Cervantes - con sus tres partes - en una versión culta del «cuento de los tres hermanos», descartando cualquier otro modelo hipotético. E incluso en casi todas las variantes populares de este los rescatadores son perseguidos por el dragón, lo que sugiere que Cervantes quizá conociera alguna versión oral al margen de Truchado ${ }^{23}$.

Cabría situar, en consecuencia, como muy probable aunque no única, la fuente directa de la «Novela del capitán cautivo» en el Segundo Libro de Straparola impreso por Francisco Truchado en 1581. Pero Cervantes no se limita a dar otra versión del cuento, sino que lo reestructura muy libremente aunque sin omitir detalles precisos.

23. Así lo vienen a apuntar otros aspectos menores. «En un lugar de las montañas de León tuvo principio mi linaje» (Quijote, I, 39: 230). «Era una familia que vivía en una montaña: allí vivía el padre con cuatro hijos: no tenían madre. Etaban [sic] en aquella montaña, arrodeada de árboles grandes», cuento de Tejeira (en las montañas leonesas del Bierzo) transcrito por Camarena (1991: I, 269). Recuérdese lo apuntado sobre el reparto en vida de la herencia paterna, que debería entregarse a quien encontrara la cosa más rara del mundo (Ruiz Sánchez 2014: 11-13). 


\title{
HERNÁN NÚÑEZ: «IGLESIA O MAR O CASA REAL»
}

\author{
Cervantes pone en boca del padre de los tres hermanos:
}

\begin{abstract}
Hay un refrán en nuestra España, a mi parecer muy verdadero, como todos lo son, por ser sentencias breves sacadas de la luenga y discreta experiencia; y el que yo digo dice: «Iglesia o mar o casa real», como si más claramente dijera: "Quien quisiere valer y ser rico siga o la Iglesia o navegue, ejercitando el arte de la mercancía, o entre a servir a los reyes en sus casas»; porque dicen: «Más vale migaja de rey que merced de señor». Digo esto porque querría y es mi voluntad que uno de vosotros siguiese las letras, el otro la mercancía, y el otro sirviese al rey en la guerra, pues es dificultoso entrar a servirle en su casa; que ya que la guerra no dé muchas riquezas, suele dar mucho valor y mucha fama (Quijote, I, 39: 230v).
\end{abstract}

Desistiremos de analizar el segundo refrán — pese a su relevancia, rebasaríamos los límites del presente estudio- para centrarnos en los valores contextuales del primero.

Suele citarse tal como lo escribe el autor. Pero sabido es que Cervantes no tenía por costumbre enunciar sino el comienzo o la primera mitad de las paremias. Lo curioso es que no haya rastro de esta en toda la Edad Media, y que solo se encuentre a partir de Hernán Núñez, Refranes o proverbios en romance (Salamanca: Juan de Cánova, 1555), f. 59v: «Iglesia o mar o casa real, quien quiere medrar»; f. $125 \mathrm{v}$ añade una variante: «Tres cosas hacen al hombre medrar: sciencia y mar y casa real» ${ }^{24}$.

Durante más de dos siglos se ha reiterado a este respecto un error grave, y más recientemente, otros cuatro, que es preciso enmendar. En primer término, suele atribuirse la segunda versión a Lope de Vega, Dorotea, I: 7 (ed. Morby, 123, con lectura «ciencia» por «sciencia») ${ }^{25}$; pero el Fénix se limita a citar a Hernán Núñez textualmente, de igual forma que en 1627 lo hará Gonzalo Correas ${ }^{26}$. Así pues, suele desconocerse que una y otra versión, y no solo la primera, se encuentran entre los Refranes de Núñez. Un segundo error consecuencia del anterior consiste en suponer menos arcaica la segunda ver-

24. Ed. crítica de Combet et al., n. 3743 y 7912. No faltan ambas versiones en repertorios paremiológicos recientes, entre refranes de intención similar: «Iglesia o mar o casa real quien quiera medrar», con variante que señalamos en cursiva (Martínez Kleiser 1953: n. ${ }^{\circ}$ 57008), remite a Hernán Núñez y Rodríguez Marín; «Iglesia, mar y casa real hacen y deshacen e los hombres» (n. ${ }^{\circ}$ 57009), a Rodríguez Marín, como las dos entradas siguientes: «Armas, letras y dineros hacen hijos caballeros» (n. $\left.{ }^{\circ} 41835\right)$ y «Costumbres, armas, letras y dineros hacen hijos caballeros» (n. ${ }^{\circ} 13839$ ), en Correas «Costumbres y dineros hacen hijos caballeros» (Vocabulario 429). Este mismo autor incluía otro refrán coetáneo similar: «Por letras, guerra y mar vienen los hombres a medrar» (473).

25. Se originó en las eds. de Pellicer (III: 74-75, n. 1) y Clemencín (III: 146, n.), que solo citan a Lope, y persiste hasta ed. Rico 2015 (II: 476, n. 494.8), así como en todos los autores que las siguen.

26. «Iglesia o mar o casa real, quien quiere medrar» y «Tres cosas hacen al hombre medrar: Iglesia y mar y casa real; o ciencia y mar y casa real» (Vocabulario 164, 512), fundiendo las dos variantes de Núñez. 
sión que la cervantina ${ }^{27}$. En tercer lugar, se atribuye a Correas haber añadido como glosa la segunda mitad del primer refrán («quien quiere medrar») ${ }^{28}$, lo que desmentiría Lope de Vega, a juicio de Bizzarri, quien propone otra teoría no menos arriesgada, en cuarto lugar: una inversión en el orden de la paremia $^{29}$. Este mismo autor opina, por último, que se trata «de un difundido refrán» (2015: 293); en realidad, y como ya queda indicado, todas las citas - más bien escasas - proceden de Hernán Núñez.

Cervantes hubo de manejar con toda seguridad los Refranes de Núñez ${ }^{30}$. Como Lope y Correas, quizá también leyera el refrán en la segunda edición de 1578 (Salamanca, Antonio de Lorenzana), o incluso en la más tardía de 1602 (Valladolid, L. Sánchez) $^{31}$, cuando decidió incluir la historia corta en el Quijote. Ambas ediciones no muestran apenas variantes y disponen los refranes por orden alfabético, como en 1555 .

Analicemos dos menciones más. En 1613, «La gitanilla» vuelve a citar la forma abreviada cervantina: los gitanos «somos gente que vivimos por nuestra industria y pico, y sin entremeternos con el antiguo refrán: "Iglesia o mar o casa real"» (Novelas 20). Antes lo glosaba Sebastián de Horozco: «Iglesia o mar / o casa real» ${ }^{32}$, en una obra inédita concluida poco antes de su muerte, entre enero y mayo de 1579 (García, García y Raigal 1996: 50), e iniciada

27. Sevilla Arroyo y Rey Hazas: «Lope de Vega, entre otros, recoge una versión más reciente» (ed. Quijote 485, n. 8); siguen ed. Murillo: «Aparece en forma más completa y moderna» que en Cervantes (I: 474, n. 5). Sobre la supuesta «modernidad», recuérdese que la Teología se anteponía a las demás sciencias.

28. Bizzarri (2015: 293) afirma citar a Combet, sin precisar la fuente; y según queda indicado, Correas se limita a transcribir a Núñez. Comete Bizzarri otros errores, como afirmar que «la antigüedad del refrán puede estar delatada por su léxico, aunque ello nos impida datarlo», pues Núñez «no utiliza el coordinante con su valor adversativo, sino con su primitivo valor copulativo» (2015: X) o con este «uso arcaico del coordinante 'o'» (293), aun cuando el nexo no comporta uno ni otro sentido, sino disyunción incluyente aún en vigor; según explica, Clemencín no habría entendido tal significado.

29. «Lo que presumiblemente pudo suceder es que inconscientemente la versión que toma Correas invirtiera el orden de los miembros del refrán. Lo que no podemos saber es si esa inversión tuvo carácter tradicional o si se trata solo de una confusión de Hernán Núñez que luego se perpetuó» (2015: 293). Renunciamos a interpretar el sentido que da Bizzarri a sus palabras.

30. Sin embargo, pese a «su mención explícita en el texto de la novela, no sabemos si [Hernán Núñez] fue una influencia importante» (Cull 2014: 150-151); el crítico no localiza el refrán citado en otros autores (156), pese a buscarlo en Feliciano de Silva, Blasco de Garay o Mosén Pedro Vallés, entre 1534 y 1549.

31. «Iglesia, o mar, o casa real, quien quiere medrar» (ed. 1578, f. 166r; ed. 1602, f. 117r); «Tres cosas hacen al hombre medrar, sciencia, y mar, y casa real» (ed. 1578, f. 448v; ed. 1602, f. 416r lee «ciencia», como en Lope de Vega). Madroñal (2002: 36), sobre ed. 1578: «Es curioso el dato que señala que el libro era ya difícil de encontrar tan pocos años después de su primera edición», según la licencia.

32. «Deja el nido en que has vivido / con tus padres regalado, / surca el mar embravecido / si quieres volver medrado y en poco tiempo lucido. / Ya que iglesia catedral / no te da ganancia igual / ni casa de rey te es yedra, / navega, que el mar es medra, si iglesia y casa real» (Teatro universal 300, n. ${ }^{\circ}$ 1364). Señalamos en cursiva una doble referencia al verbo medrar en la parte omitida del refrán. Con todo, el índice («Síguense todos los proverbios, adagios y refranes que en este volumen se contienen por la orden del alfabeto para que más brevemente se puedan hallar») ofrece una variante: «Iglesia $y$ mar $y$ casa real» (699). 
después de 1558 (ed. 1986: 22), ya a la venta los Refranes. Es muy probable que Horozco recogiera el refrán de Hernán Núñez; Cervantes, si no conoció esta fuente originaria, parece difícil que adoptara la forma breve de Horozco.

Como recuerda Clemencín en su edición del Quijote (III: 146, n.), el economista toledano Sancho de Moncada volvía a citar en 1619 el mismo comienzo del refrán «Iglesia o mar o casa real», a propósito de las mercaderías, en su opúsculo Restauración política de España (cap. XVIII). No interesa ahora revisar el pensamiento de este autor ni valorar su figura (Fernández Delgado 2003). Moncada pudo tomar prestado el refrán de los autores expuestos, cuando no directamente de Cervantes.

Atendiendo a los textos históricos, Fayard (1979: 329) comprueba en buena parte de la nobleza el cumplimiento del refrán, incluso después del Quijote. Y también mucho antes. No obstante, Elliott (1972: 339) descarta el comercio ultramarino entre los oficios habituales del siglo XVII, reduciéndolos a la iglesia o al servicio al rey; y Salazar Rincón (1986: 124) asigna a los hidalgos las armas y las letras. Sin ánimo de enmendar al autor, añadiremos a su glosa una lectura más cercana al lector actual. Quien pretendía en la época un ascenso social sin pertenecer a una familia noble o siendo un segundón, podía ordenarse sacerdote y cursar una carrera universitaria para aspirar a cargos eclesiásticos. Más fácil era dedicarse al comercio, para lo que tampoco se precisaba limpieza de sangre. En cuanto a la Casa Real, conformaba «un universo de criados» en oficios domésticos, en las Caballerizas y en la Real Capilla (Barrios 2005: 80); en verdad, se dividía en la Casa del Rey, la de la Reina, la de la Reina Madre y la de Castilla (Jurado 2005); antes de los Refranes de Núñez muchos autores se refirieron a esta posibilidad de medrar ${ }^{33}$ — voz siempre reiterada-, aunque no faltaran quienes desmentían tan optimista visión ${ }^{34}$. Según Martínez Ruiz (2005: 107), servir al rey en la guerra ofrecía al soldado «la posibilidad de mejorar su situación económica», por considerarse el ejército «vehículo de promoción social», si bien los pagos exiguos, percibidos con retraso, revelan lo contrario.

33. Desde las Epístolas familiares (1521-1543) de fray Antonio de Guevara: «Estáis en la Casa Real, adonde todos los buenos se crían y a do todos los que sirven medran, y si de allí alguno no sale augmentado, o sale de allí desmedrado, no es por culpa del príncipe, que sea desagradescido, sino del criado, que en su servicio ha sido descuidado» (CORDE). En su Libro de la Cámara Real del príncipe don Juan (1548), Gonzalo Fernández de Oviedo afirma: «Ningún oficio hay en la Casa Real que no sea muy honrado, e aqueste de mozo de espuelas e de la ballesta tienen mucho aparejo, cuando son hombres de habilidad, para medrar e ser más que otros», pues «aciertan algunos dellos a servir tan bien que, de aquel oficio, pasan a otros más honrados e provechosos en la Casa Real, e se les hacen mercedes e tienen lugar para pedirlas e haberlas en muchos tiempos» (128), antes de ofrecer varios casos personales; fueron pajes del príncipe, no solo hijos de grandes, sino también «de caballeros ilustres sin título» (91); el editor, Fabregat Barrios, destaca «ese medro, tantas veces nombrado en el Libro» (53, y véase 91, n. 45).

34. Pedro de Navarra, en sus Diálogos de la preparación de la muerte (1565), ya debe reconocer: «Los oficios de la Casa Real» se sustentan «con esperanzas de medrar y valer, y las más veces primero te acuerdas tú [la Muerte] de llevarlos que el rey los llame para amejorarlos» (Gómez Ramos II: 155). 
No sin cautela opinaban Schevill y Bonilla que tal vez «Cervantes, influido por el refrán de "Iglesia o mar o casa real"», hallase en él «ya indicadas las tres carreras de los tres hijos» (ed. Quijote II: 443, n. 203-29). Hemos visto que ocurre todo lo contrario: el cuento de Truchado haría evocar a Cervantes el refrán de Hernán Núñez. Es más, las tres vías se cumplen a medias: nadie sigue la Iglesia, sustituida por la carrera de leyes; la Casa Real es reemplazada por la milicia en boca del padre; y solo el hijo menor elige el oficio de mercader. Tampoco el orden de las profesiones corresponde al de los tres hermanos. Y solo uno conseguirá triunfar desde el punto de vista económico.

Acaso el refrán fuera más propio de Portugal que de España, por asociar al poder del clero y al comercio una sobredimensionada casa real, aun cuando el primer repertorio paremiológico luso sea el propio refranero de Núñez (ed. 2001: 269). Antonio Delicado, en sus Adagios portuguezes de 1651, donde reconoce haber consultado al autor junto con Mal Lara y Blasco de Garay («Ao leitor», a3r), incluye las dos variantes del Comendador al pie de la letra: «Tres cousas fazem ao homem medrar, sciencia, \& o mar \& casa Real» (75), «Igreja, ou mar, ou casa Real» $(170)^{35}$. Lo mismo que en otros países sin casa real ocurre en Italia ${ }^{36}$. Nada similar hallamos en Le dieci tavole dei proverbi (Turín, 1535) ni en los Proverbi italiani (Verona, 1598 y Venecia, 1603) de Orlando Pescetti.

Con todo, siendo así que Hernán Núñez recogió en su libro refranes portugueses, gallegos, asturianos, franceses, italianos, catalanes y aragoneses, y que faltan entre ellos las dos variantes castellanas, tampoco ha de rastrearse ahí su origen.

Ningún otro repertorio contiene un refrán siquiera análogo: hemos de suponer que forma parte de los que recopiló Hernán Núñez de fuentes orales o quizá de los que le comunicó Juan Páez de Castro, supuesto coautor de la obra (ed. 2001: XII, Madroñal 2002: 18-19). Llegados a uno o varios posibles informantes sin registrar, no cabe ir más lejos. Y ya que Cervantes, como todos los autores que lo citan, parte de los Refranes de Núñez, nos hemos ceñido a esta única fuente, de igual modo que cuando analizábamos el cuento de Straparola vertido por Truchado al castellano.

35. Las transcribe apenas sin cambios Domingos Chaves (s. d.: 196, n. ${ }^{\circ} 13$, y 412, n.o 301 ) «Quem quiser medrar, Igreja, Casa Real ou mar», reza otra variante, o «Tres coisas fazem o homem medrar, a Ciencia, a Casa Real e o mar», que Júlio de Castilho data del siglo XV sin aportar razón (Caratão s. d.: 35).

36. Cierta edición de Proverbi italiani (1886) que atribuía el texto a un Francesco d'Ambra — sin duda un crítico homónimo del dramaturgo florentino (1499-1558) - contiene las dos variantes de los Refranes: «Scienza, casa, mare, molto fan l'uomo avanzare - ovvero: Tre cose fan l'uomo guadagnare, scienza, corte e mare» (220). En la Raccolta de Giuseppe Giusti (ed. 1853) se lee: «Scienza, casa, virtù e mare, molto fa l'uomo avanzare» (117). Pero desde la versión ampliada por Gino Capponi (ed. 1871) ya aparecen textualmente los dos refranes de d'Ambra (110); y una «Avvertenza» (II) reconoce haber consultado la edición de Hernán Núñez de 1555, a la que debiera añadirse la de Correas. 


\section{CERVANTES EN BAEZA, INVIERNO DE 1591-1592}

Creemos haber probado la dependencia de la «Novela del capitán cautivo» respecto a la segunda parte de la versión castellana de los cuentos de Straparola, editada por Francisco Truchado, baezano y bedel de la Universidad de Baeza, en esta ciudad y en la imprenta de Juan Bautista de Montoya el año 1581 , con reediciones de 1582 y 1583 , y quizá incluso otra más, posterior a julio de 1588 (Cátedra 2001: 223-233, 245, n. ${ }^{\circ} 43,44,46,52$ ). Truchado se nos antoja, ya que no un alter ego de Miguel de Cervantes, sí al menos un curioso personaje que compartía con él varios rasgos de interés: nacido probablemente el mismo año de 1547, conocía la literatura italiana (de donde su afición a las novelas cortas), pasó por la cárcel y fue soldado en su juventud, acaso en Italia; el título cervantino Novelas ejemplares de honestísimo entretenimiento recuerda en exceso el Honesto y agradable entretenimiento con que Truchado moraliza Le piacevoli notti de Straparola; no coincidían, por descontado, los niveles de destreza literaria en Cervantes y Truchado (Federici I: 17-18, 30-33). Han de completarse estos datos con los más precisos de Rubio Árquez (2013), sobre la ejemplaridad de sus obras, y de Coppola (2012), quien demuestra, entre otros aspectos, que el traductor se basó en la edición de Straparola de 1565 (142). Desconocemos qué ocurrió entre las fechas del 3 de noviembre de 1574 (licencia real) y del 25 de junio de 1578 (licencia eclesiástica de Zaragoza), previa a la primera edición de la segunda parte del libro en 1581, pero que hubo problemas contractuales o de otra índole lo sugiere el retraso de siete años (González Ramírez 2011a: 1229-1230). Si los cuentos de Straparola acabaron siendo prohibidos y la versión de Truchado, depurada por López de Hoyos, siempre despertó sospechas pese a su título, Cervantes también hubo de buscar excusas moralistas a sus novelas cortas más atrevidas.

De los tiempos del cautiverio debe citarse a baezanos o residentes conocidos de Cervantes. Entre ellos, a fray Antón de la Bella, implicado en el rescate de Miguel; no deja lugar a dudas la estrecha relación de amistad con don Diego de Benavides, antes y después de ser liberados ambos; trató asimismo a Juan de Villalta.

Once años después el autor se encontraba en la ciudad de Baeza ocupado en sus comisiones jienenses. Astrana Marín (1948-1958, IV: 492-497) situó allí a Cervantes en $1591^{37}$. Arrojan mayor precisión los documentos exhumados por Coronas Tejeda (1979). Entre ellos, una carta de pago extendida por Cervantes, el 14 de julio de 1592, «por el tiempo que serví a Su Majestad en la saca y conducción del trigo de la ciudad de Jaén, Úbeda y Baeza» (21); el

37. Desde abril de 1591 el autor habría realizado muchas sacas de trigo en Jaén, Úbeda, Baeza y otros pueblos (IV: 492), pero la estancia en Úbeda «corresponde al otoño de 1591, y no al año 1592» (494); también en 1591 pudo ver en Baeza a don Diego de Benavides y a Juan de Villalta, si no había muerto (497), conjetura sin base alguna. Desde enero de 1592 a mayo se encontraría en tierras de Jaén, donde Astrana (V: 7-13) nombra varios pueblos, aunque no Baeza. 
lapso de la gestión comprende desde el 2 de octubre de 1591 hasta el 30 de junio de 1592. Cervantes pasó en Jaén y alrededores el invierno de 1591. Hacía diez, nueve y ocho años -incluso tres o menos, de haberse reeditado hacia 1588 - se publicaba la Segunda parte de Truchado, libro de no fácil acceso en Madrid, Toledo o Esquivias; acaso tampoco en Sevilla, Écija y otros lugares donde estuvo encargado Cervantes de sus comisiones, entre el 22 de septiembre de 1587 y el 12 de marzo de 1591. Antes de la edición de Madrid (Luis Sánchez, 1598) con las dos partes, no había otra de la segunda que las de Baeza. ¿Llegaría el libro a manos de Cervantes en esta ciudad el invierno de 1591-1592? ¿Consultó la edición madrileña de 1598 al insertar la «Novela» en el Quijote? Recuérdese que sugeríamos la lectura en 1602 de los Refranes de Núñez, en línea con la adopción del nombre Zoraida tomado de Gilbau después de 1600 .

Baeza era ciudad episcopal, contaba con universidad ${ }^{38}$ y de la imprenta de Juan Bautista de Montoya salían a luz obras de primer orden (Cátedra 2001). Desconocemos si aquel invierno trató Cervantes con Manuel III de Benavides y Bazán — quinto señor de Jabalquinto (1574-1617) y futuro primer marqués, que tomó parte en Lepanto, bibliófilo y gran aficionado a la poesía ${ }^{39}$, cuyo magnífico palacio renacentista se alzaba en la propia Baeza-, o con algún otro Benavides, o con qué autores pudo tener relación, habida cuenta de la rica actividad literaria y artística baezana de que ha dado cuenta Argente (1985). Otros nombres guardan una relación más indirecta con el autor ${ }^{40}$. Una vez alude Cervantes a la ciudad, cuando el bachiller Alonso López, natural de Alcobendas, dice haber salido de allí «con otros once sacerdotes» en dirección a Segovia, para enterrar el cadáver «de un caballero que murió en Baeza, donde fue depositado» (Quijote I, 19: 82v); suele asociarse el episodio con la muerte de san Juan de la Cruz en Úbeda la noche del 13 al 14 de diciembre de 1591, hallándose Cervantes en esta zona ${ }^{41}$.

Fijémonos en la fecha generalmente propuesta para la «Novela». «Este hará veinte y dos años que salí de casa de mi padre» (I, 39: 231v), poco antes de la llegada del duque de Alba a Flandes el verano de 1567, refiere Pérez de

38. Moreno Uclés (1995) destaca el foco humanístico de la Universidad de Baeza, fundada por Rodrigo Pérez de Molina, donde Juan de Ávila impulsó un nuevo modelo ortodoxo de espiritualidad interior en relación parcial con Erasmo pero no con los alumbrados; insiste Moreno en el origen judeoconverso de los primeros titulados y profesores, sin excluir al fundador y al maestro Ávila; y cita gran número de discípulos baezanos o estudiantes adscritos a la Universidad (224-289). Véase Ortega Ruiz (2015).

39. Se conservan dos sonetos suyos, a la Primera parte de La Angélica (Granada, Hugo de Mena, 1586), de Luis Barahona de Soto, y al Conocimiento, curación y preservación de la peste, del doctor Alonso de Freylas (Jaén, Fernando Díaz de Montoya, 1606), donde consta otro de su hijo Juan Francisco de Benavides.

40. De Huarte de San Juan, que fuera médico titular de la ciudad entre 1572 y 1588 , muerto en Linares, Juan Bautista de Montoya había editado el Examen de ingenios para las ciencias (Baeza, 1575), obra conocida por Cervantes, que también pudo leer a Gaspar de Baeza, natural de esta ciudad y traductor de Paulo Jovio. Nacido en Almodóvar del Campo, el manchego san Juan Bautista de la Concepción estudió teología en la Universidad de Baeza.

41. Había fundado el santo el Colegio Descalzo de Baeza, del que fue rector en 1579-1582. 
Viedma. Así pues, la acción se data en 1589-1590 (ed. Murillo, I, 472-473, n. 1) o «entre 1588 y 1590, según se cuente» (ed. Rico I, 496, n. 17); más tarde, el relato habría sido intercalado en el Quijote. Dando al verbo hará valor de cálculo aproximado, el año que debe contarse se extendería desde la primavera de 1589 al invierno de 1589-1590, tras el cual se cumpliría el vigesimotercero. Cervantes parece estar contando en Baeza hechos acaecidos menos de dos años antes de la escritura, lapso temporal acorde con sus hábitos creativos.

Hay más. Allen (1976: 151-155) asoció la autobiografía ficticia del autor con un documento: el 21 de mayo de 1590 Cervantes presentaba al rey un memorial para solicitar oficio en las Indias, recordando su carrera militar en Lepanto y en Navarino, Túnez y la Goleta; ya es sabida la negativa del 6 de junio. Habiendo cursado la milicia, y descartada la vía religiosa, de las tres opciones para medrar solo quedaba la aventura personal del Nuevo Mundo ${ }^{42}$. Aquí interesan tanto la coincidencia temporal como las empresas bélicas comunes a la «Novela» (Murillo 1981). Tras fracasar el texto legal, el ficticio volvía a incluir estos servicios año y medio después atribuyéndolos a Pérez de Viedma ${ }^{43}$.

¿Conocería Cervantes a Francisco Truchado en Baeza? De lo que no cabe duda es de que entre 1581 y 1592 hubo de leer su versión de Straparola. Lo prueban variantes narrativas exclusivas de Truchado y Cervantes, pero asimismo razones geográficas, cronológicas e incluso vitales. Todos los datos hasta ahora enumerados, y otros que reservamos para un futuro trabajo, vienen a coincidir sin la menor divergencia.

De un tiempo a esta parte, la crítica cervantina, huyendo de reiterar puntos de vista consabidos, se esfuerza por descubrir nuevas vías de análisis para conocer mejor la obra de Cervantes. Sirva este ensayo como un modesto paso con igual objetivo.

\section{BIBLIOGRAFÍA CITADA}

Aarne, Antti y Stith Thompson $(1928,1961)$. The Types of the Folk-Tale. A Classification and Bibliography. Helsinki: FFC.

Allen, John J. (1976). «Autobiografía y ficción: el relato del Capitán cautivo (Don Quijote, I, 39-41)», Anales Cervantinos. 15, pp. 149-155.

42. Aunque el sueño americano se había devaluado a fines del siglo XVI, poco antes de que Juan Pérez de Viedma fuera a desempeñar el cargo de oidor en la Audiencia de México, su creador pedía uno de los cuatro destinos por entonces vacantes: contador del Nuevo Reino de Granada, gobernador de la provincia de Soconusco en Guatemala, contador de las galeras de Cartagena o corregidor de la ciudad de La Paz (Martínez Shaw 2005: 100-104, donde se cita el refrán del Quijote).

43. No faltan otras discrepancias respecto a la carrera del capitán, que Allen (1976) trata de salvar suponiendo una empresa de Cervantes en Flandes; le falta añadir el cautiverio en Constantinopla. De momento no es posible abordar tales aspectos. 
Argente del Castillo Ocaña, Concepción (1985). «La producción literaria en Baeza (siglos XVI y XVII)», en José Rodríguez Molina (coord.), Historia de Baeza: Historia, Literatura, Arte. Baeza: Ayuntamiento / Universidad de Granada, pp. 333-390.

Astrana Marín, Luis (1948-1958). Vida ejemplar y heroica de Miguel de Cervantes Saavedra. Madrid: Reus, 6 tomos y 7 vols.

ATU: Uther, Hans Jörg (2004). The Types of International Folktales. A Classification and Bibliography, Based on The System of Antti Aarne and Stith Thompson. Helsinki: Suomalainen Tiedeakatemia-Academia Scientiarum Fennica.

Barrios, Feliciano (2005). «La atracción de la Corte: burócratas y pretendientes», en $E l$ mundo que vivió Cervantes. Madrid: Sociedad Estatal de Conmemoraciones Culturales, pp. 78-87.

Bizzarri, Hugo O. (2009). «Introduction: Le passage du proverbe à l'exemplum et de l'exemplum au proverbe», en Hugo O. Bizzarri y Martin Rohde (eds.), Tradition des proverbes et des exempla dans l'Occident médiéval. Berlín: De Gruyter, pp. 7-24.

Bizzarri, Hugo O. (2015). Diccionario de paremias cervantinas. Alcalá de Henares: Universidad.

Bleda, Jaime (1618). Corónica de los moros de España. Valencia: Felipe Mey.

Camarena, Julio (1991). Cuentos tradicionales de León. Madrid: Universidad Complutense / Diputación Provincial de León, 2 vols.

Camarena, Julio y Maxime Chevalier (1995). Catálogo tipológico del cuento folklórico español. Cuentos maravillosos. Madrid: Gredos.

Capponi, Gino (1871). Raccolta di proverbi toscani nuovamente ampliata da quella di Giuseppe Giusti. Florencia: Successori Le Monnier.

Caratão Soromenho, Paulo (s. d.). «Roteiro Fraseológico de Lisboa (Notas Complementares)», Olisipo. 139-140, pp. 26-42.

Carrasco Urgoiti, María Soledad (1996). El moro retador y el moro amigo. Estudios sobre fiestas y comedias de moros y cristianos. Granada: Universidad.

Casalduero, Joaquín (1970). Sentido y forma del «Quijote». Madrid: Ínsula.

Castillo Solórzano, Alonso de (1636). Patrón de Alcira, el glorioso mártir san Bernardo, de la Orden del Cistel. Zaragoza: Pedro Berges.

Cátedra, Pedro M. (2001). Imprenta y lecturas en la Baeza del siglo XVI. Salamanca: Seminario de Estudios Medievales y Renacentistas.

Cervantes Saavedra, Miguel de (1605). El ingenioso hidalgo don Quijote de la Mancha. Madrid: Juan de la Cuesta.

Cervantes Saavedra, Miguel de (1613). Novelas ejemplares. Madrid: Juan de la Cuesta.

Cervantes Saavedra, Miguel de (1797-1798). El ingenioso hidalgo don Quijote de la Mancha, Juan Antonio Pellicer (ed.). Madrid: Gabriel de Sancha, 5 vols.

Cervantes Saavedra, Miguel de (1833-1839). El ingenioso hidalgo don Quijote de la Mancha, Diego Clemencín (ed.). Madrid: Aguado, 6 vols.

Cervantes Saavedra, Miguel de (1928-1941). Don Quixote de la Mancha, Rodolfo Schevill y Adolfo Bonilla (ed.). Madrid: Gráficas Reunidas, 4 vols.

Cervantes Saavedra, Miguel de (1978). El ingenioso hidalgo don Quijote de la Mancha, Luis Andrés Murillo (ed.). Madrid: Castalia, 3 vols.

Cervantes Saavedra, Miguel de (1996). Don Quijote de la Mancha I, en Obra completa $I V$, Florencio Sevilla Arroyo y Antonio Rey Hazas (eds.). Madrid: Alianza.

Cervantes Saavedra, Miguel de (2015). Don Quijote de la Mancha, Francisco Rico (dir.). Madrid: Real Academia Española, 2 vols.

Cervantes Saavedra, Miguel de (2015). «Comedia famosa de Los baños de Argel», Alfredo Baras Escolá (ed.), en Luis Gómez Canseco (coord.), Comedias y tragedias. Madrid: Real Academia Española, 2 vols. 
Chaves, Domingos (s. d.). Rifoneiro Português. Oporto: Domingos Barreira.

Chevalier, Maxime (1981). «Huellas del cuento folclórico en el Quijote», en Manuel Criado de Val (ed.), Cervantes, su obra y su mundo (Actas del I Congreso Internacional sobre Cervantes). Madrid: Edi-6, pp. 881-893.

Chevalier, Maxime (1983). «El cautivo entre cuento y novela», Nueva Revista de Filología Hispánica. 32 (2), pp. 403-411. https://doi.org/10.24201/nrfh.v32i2.559.

Chevalier, Maxime (1999). «Fórmulas de cuentos tradicionales en textos del Siglo de Oro», en Cuento tradicional, cultura, literatura (siglos XVI-XIX). Salamanca: Universidad, pp. 29-38.

Coppola, Leonardo (2012). «Traducción y dispositio: Truchado e Le piacevoli notti», Dicenda. Cuadernos de Filología Hispánica. 30, pp. 141-152. https://doi.org/10.5209/ rev_dice.2012.v30.41367.

Coppola, Leonardo (2013). «Prolegómenos a la edición del Honesto y agradable entretenimiento de damas y galanes», en Alain Bègue y Emma Herrán Alonso (dirs.), Pictavia Aurea. Actas del IX Congreso de la Asociación Internacional Siglo de Oro (Poitiers, 11-15 de julio de 2011). Toulouse: Presses Universitaires du Mirail, pp. 367-374.

CORDE (Corpus diacrónico del español). Madrid: Real Academia Española. Accesible en: $<\mathrm{http}: / /$ www.rae.es $>$.

Coronas Tejeda, Luis (1979). «Cervantes en Jaén, según documentos hasta ahora inéditos», Boletín del Instituto de Estudios Giennenses. 99, pp. 9-52.

Correas, Gonzalo (1967). Vocabulario de refranes y frases proverbiales (1627), Louis Combet (ed.). Burdeos: Féret et Fils.

Cull, John T. (2014). «Nunca mucho costó poco. Una vez más sobre las paremias del Quijote», Paremia. 23, pp. 147-161.

Dadson, Trevor J. (2007). Los moriscos de Villarrubia de los Ojos (siglos XV-XVIII). Historia de una minoría asimilada, expulsada y reintegrada. Madrid y Fráncfort: Iberoamericana / Vervuert.

D’Ambra, Francesco (1886). Proverbi italiani: ordinati e illustrati. Florencia: Adriano Salani.

Darbord, Bernard y Alexandra Oddo (2008). «La parole proverbiale de Juan Ruiz, dans le Libro de Buen Amor», en Thomas Gómez y Marie Claude Chaput (eds.), Mélanges en hommage à Madeleine et Arcadio Pardo. Nanterre: Université Paris X-Nanterre, pp. 61-91.

Darnis, Pierre (2013). «¿Por qué y cómo son ejemplares las Novelas ejemplares? (I) Una vuelta a los conceptos de mímesis y ética», Artifara. 13 bis, pp. 7-32.

Delicado, Antonio (1651). Adagios Portuguezes reduzidos a lugares communs. Lisboa: Domingos Lopes Rosa.

Diago, Francisco (1613). Anales del reino de Valencia. Tomo primero. Valencia: Pedro Patricio Mey.

Elliott, John H. (1972). La España Imperial, 1469-1716. Barcelona: Vicens Vives.

Escolano, Gaspar (1611). Segunda parte de la década primera de la Historia de la insigne y coronada ciudad y reino de Valencia. Valencia: Pedro Patricio Mey.

Espinosa, Aurelio Macedonio (1946-1947). Cuentos populares españoles, recogidos de la tradición popular de España. Madrid: CSIC, 3 vols.

Espinosa, Aurelio Macedonio, hijo (1987). Cuentos populares de Castilla y León. Madrid: CSIC, vol. 1.

Fansler, Dean S. (1921). Filipino Popular Tales. Lancaster y Nueva York: The American Folk-Lore Society.

Farnham, Willard Edward (1920). «The Contending Lovers», Publications of the Modern Language Association of America. 35 (3), pp. 247-323. https://doi.org/10.2307/457138. 
Fayard, Janine (1979). Les membres du Conseil de Castille à l'époque moderne (16211746). Ginebra: Librairie Droz.

Federici, Marco (2011). Edizione di Francisco Truchado «Honesto y agradable entretenimiento de damas y galanes» (1569-1612). Roma: Università «La Sapienza», tesis doctoral, 3 vols.

Fernández de Oviedo, Gonzalo (2006). Libro de la Cámara Real del príncipe don Juan, oficios de su Casa y servicio ordinario, Santiago Fabregat Barrios (ed.). Valencia: Universitat de València.

Fernández Delgado, Rogelio (2003), La ruptura del pensamiento económico castellano en el siglo XVII: Juan de Mariana y Sancho de Moncada. Madrid: Universidad Complutense, tesis doctoral.

Frutos Martínez, María Consuelo (1998). «Análisis temático y cultural de los Refranes que diçen las viejas tras el fuego, del Marqués de Santillana», en Giovanni Ruffino (ed.), Atti del XXI Congresso Internazionale di Linguistica e Filologia Romanza. Tübingen: Max Niemeyer, pp. 613-623.

García Cañete, Marta, Inmaculada García Carretero y Encarna Raigal Pérez (1996). «Nuevos datos sobre Sebastián de Horozco y su refranero», Paremia. 5, pp. 49-58.

Gilbau, Honorato (1600). Libro de la vida, martirio y algunos milagros de S. Bernardo mártir, natural del territorio de la villa de Alcira. Valencia: sin editor.

Giusti, Giuseppe (1853). Raccolta di proverbi toscani con illustrazioni cavata dai manoscritti di - ed ora ampliata ed ordinata. Florencia: Felice Le Monnier.

Gómez Ramos, Emiliano (2004). Pedro de Navarra: estudio biobibliográfico. Recopilación de las obras manuscritas e impresas. Edición crítica y autoría de los «Diálogos de las herejías de Francia». Almería: Universidad, tesis doctoral, 3 vols.

Gómez Vozmediano, Miguel Fernando (2000). Mudéjares y moriscos en el Campo de Calatrava. Reductos de convivencia, tiempos de intolerancia (siglos XV-XVII). Ciudad Real: Diputación Provincial.

González Ramírez, David (2011a). «En el origen de la novela corta en España: los novellieri en España», Arbor. 187 (752), pp. 1221-1243. https://doi.org/10.3989/ arbor.2011.752n6016.

González Ramírez, David (2011b). «La prínceps del Honesto y agradable entretenimiento de damas y galanes (Zaragoza, 1578) de Straparola: hallazgo de una edición perdida», Analecta Malacitana. 34 (2), pp. 517-528.

Guerrero Arjona, Melchor (2007). «El dominio del territorio: la repoblación cristiana del Marquesado de los Vélez tras la guerra de las Alpujarras», Revista Velezana. 26, pp. 37-48.

Haedo, Diego de (1612). Topografía e historia general de Argel. Valladolid: Diego Fernández de Córdoba.

Horozco, Sebastián de (1986). Teatro universal de proverbios, José Luis Alonso Hernández (ed.). Salamanca: Universidad.

Jurado Sánchez, José (2005). La economía de la corte. El gasto de la Casa del Rey en la Edad Moderna (1561-1808). Madrid: Universidad Complutense.

Labarta, Ana (1987). La onomástica de los moriscos valencianos. Madrid: CSIC.

Lada Ferreras, Ulpiano (2007). «La actio en la narrativa oral literaria», en Miguel Ángel Garrido Gallardo y Emilio Frechilla Díaz (eds.), Teoría/crítica. Homenaje a la profesora Carmen Bobes Naves. Madrid: CSIC, pp. 317-333.

Lafuente y Alcántara, Emilio (1859). Inscripciones árabes de Granada, precedidas de una reseña histórica y de la genealogía detallada de los reyes Alahmares. Madrid: Imprenta Nacional.

Le dieci tavole dei proverbi (1995). Manlio Cortelazzo (ed.). Vicenza: Neri Pozza. 
Madroñal, Abraham (2002). «Los Refranes o proverbios en romance (1555), de Hernán Núñez, Pinciano», Revista de Literatura. 64 (127), pp. 5-39. https://doi.org/10.3989/ revliteratura.2002.v64.i127.188.

Mármol Carvajal, Luis del (1600). Historia del rebelión y castigo de los moriscos del reino de Granada. Málaga: Juan René.

Márquez Villanueva, Francisco (1975). Personajes y temas del Quijote. Madrid: Taurus.

Martínez Kleiser, Luis (1953). Refranero general ideológico español. Madrid: Real Academia Española.

Martínez Ruiz, Enrique (2005). «Servir al rey. La milicia y los ejércitos del rey», en $E l$ mundo que vivió Cervantes. Madrid: Sociedad Estatal de Conmemoraciones Culturales, pp. 107-114.

Martínez Shaw, Carlos (2005). «La llamada de Indias», en El mundo que vivió Cervantes. Madrid: Sociedad Estatal de Conmemoraciones Culturales, pp. 97-104.

Moner, Michel (1988). «Du conte merveilleux à la pseudo-autobiographie: le récit du Captif (Don Quichotte, I, 39-41)», en Guy Mercadier (ed.), Écrire sur soi en Espagne. Modèles et écarts. Actes du IIIe Colloque International d'Aix-en-Provence (4-5-6 décembre 1986). Aix-en-Provence: Université de Provence, pp. 57-71.

Montaner Frutos, Alberto (2006). «Zara / Zoraida y la Cava Rumía: historia, leyenda e invención», en Nuria Martínez de Castilla Muñoz y Rodolfo Gil Benumeya Grimau (coords.), De Cervantes y el Islam, Encuentro internacional Cervantes, el «Quijote», lo moro, lo morisco y lo aljamiado (Sevilla, 19-21 de mayo de 2005). Madrid: Sociedad Estatal de Conmemoraciones Culturales, pp. 247-280.

Moreno Uclés, Juan (1995). «Humanismo giennense (siglos XV-XVIII)», Boletín del Instituto de Estudios Giennenses. 158 (octubre-diciembre), pp. 167-295.

Murillo, Luis Andrés (1975). The Golden Dial: Temporal Configuration in Don Quijote. Oxford: The Dolphin Book.

Murillo, Luis Andrés (1981). «El Ur-Quijote: Nueva hipótesis», Cervantes. 1 (1-2), pp. 43-50.

Murillo, Luis Andrés (1983). «Cervantes’ Tale of the Captive Captain», en John S. Geary, Charles B. Faulhaber y Dwayne E. Carpenter (eds.), Florilegium Hispanicum. Medieval and Golden Age Studies Presented to Dorothy Clotelle Clarke. Madison: The Hispanic Seminary of Medieval Studies, pp. 229-243.

Núñez de Toledo, Hernán (1555). Refranes o proverbios en romance. Salamanca: Juan de Cánova.

Núñez de Toledo, Hernán (1578). Refranes o proverbios en romance. Salamanca: Antonio de Lorenzana.

Núñez de Toledo, Hernán (1602). Refranes o proverbios en romance. Valladolid: L. Sánchez.

Núñez de Toledo, Hernán (2001). Refranes o proverbios en romance, Louis Combet, Julia Sevilla Muñoz, Germán Conde Tarrío y Josep Guia i Marín (ed. crítica). Madrid: Guillermo Blázquez.

Oddo, Alexandra (2015). «Refranes y sentencias en la Edad Media: estudio de algunas correspondencias», Memorabilia. 17, pp. 115-134.

Oliver Asín, Jaime (1947-1948). «La hija de Agi Morato en la obra de Cervantes», Boletín de la Real Academia Española. 27, pp. 245-339.

Ortega Ruiz, Antonio (2015). «Las Escuelas y Universidad de Estudios Generales de Baeza: 1538-1824», en Antonio Ortega Ruiz (coord.), La Universidad de Baeza. Documentos para su historia. Sevilla: Universidad Internacional de Andalucía, pp. 9-25.

Paredes Núñez, Juan (1984). «El término "cuento" en la literatura románica medieval», Bulletin Hispanique. 86 (3-4), pp. 435-451. https://doi.org/10.3406/hispa.1984.4541. 
Parodi, Alicia (1991). «El episodio del cautivo, poética del Quijote: verosímiles transgredidos y diálogo para la construcción de una alegoría», en Actas del Segundo Coloquio Internacional de la Asociación de Cervantistas (Alcalá de Henares, del 6 al 9 de noviembre de 1989). Barcelona: Anthropos, pp. 433-441.

Pedrosa, José Manuel (2004). Los cuentos populares en los Siglos de Oro. Madrid: Ediciones del Laberinto.

Pescetti, Orlando (1598). Proverbi italiani. Verona: Girolamo Discepolo.

Pescetti, Orlando (1603). Proverbi italiani. Venecia: Lucio Spineda.

Ramadori, Alicia Esther (2013). «Una tipología de las mujeres sabias en la literatura española medieval», Graphos. 15 (1), pp. 1-14.

Ranke, Klaus (1979). Enzyklopädie des Marchens: Handwörterbuch zur historischen und vergleichenden Erzählforschung. Berlín y Nueva York: Walter De Gruyter, vol. 2.

Rodríguez, Alfred y Milagro Larson (1985). «El relato-marco del "Cuento del cautivo": función narrativa y estética», Anales Cervantinos. 23, pp. 83-87.

Rodríguez Almodóvar, Antonio (1982). Antonio Rodríguez Almodóvar presenta los cuentos maravillosos españoles. Barcelona: Crítica.

Rodríguez-Moñino, Antonio (1957). Las fuentes del Romancero General (Madrid, 1600). Madrid: Real Academia Española, 12 vols.

Rodríguez-Moñino, Antonio (1973-1978). Manual bibliográfico de Cancioneros y Romanceros. Madrid: Castalia, 4 vols.

Rodríguez Valle, Nieves (2012). «"Coser y cantar”: el hilar como espacio de la transmisión oral, la lira que le canta y el refrán que lo sentencia», Olivar. 13 (18), pp. 235-253.

Rodríguez Valle, Nieves (2013). «Las viejas tras el fuego hilando en sus ruecas ¿sabios refranes o vanas consejas?», en Concepción Company, Aurelio González y Liliana von der Walde Moheno (eds.), Aproximaciones y revisiones medievales. Historia, lengua y literatura. México: El Colegio de México, pp. 295-312.

Romancero General (1600). Madrid: Luis Sánchez.

Romancero General o Colección de romances castellanos anteriores al siglo XVIII (19121916), A. Durán (ed.). Madrid: Sucesores de Hernando (BAE, X y XVI).

Rubio Árquez, Marcial (2013). «Los novellieri en las Novelas ejemplares de Cervantes: la ejemplaridad», Artifara. 14, pp. 33-58.

Ruiz Sánchez, Marcos (2014). «La princesa rescatada. La novella LXXX de G. Morlini y los cuentos populares», Tonos Digital. 27, pp. 1-29.

Salazar de Mendoza, Pedro (1625). Crónica del Gran Cardenal de España don Pedro González de Mendoza. Toledo: María Ortiz de Saravia, 2 vols.

Salazar Rincón, Javier (1986). El mundo social del «Quijote». Madrid: Gredos.

Santisteban Osorio, Diego de (1599). Primera y segunda parte de las guerras de Malta y toma de Rodas. Madrid: Várez de Castro.

Schimmel, Annemarie (1989). Islamic Names. Edimburgo: University Press.

Silveira y Montes de Oca, Jorge A. (1980). Índice de onomásticos y toponímicos contenidos en el Romancero General de Agustín Durán. Valencia y Chapel Hill: Albatros Hispanófila.

Straparola da Caravaggio, Giovanfrancesco (1567). Le piacevoli notti... Libro secondo. Venecia: Iseppo di Mantelli.

Straparola da Caravaggio, Giovanfrancesco (2012). The Pleasant Nights, Donald Beecher (ed.). Toronto: University of Toronto Press, 2 vols.

Straparola da Caravaggio, Giovanfrancesco (2016). Honesto y agradable entretenimiento de damas y galanes, trad. Francisco Truchado, Leonardo Coppola (ed.). Madrid: SIAL. 
Szpiech, Ryan (2017). «Conversion as a Historiographical Problem. The Case of Zoraya/ Isabel de Solís», en Yaniv Fox y Yosi Yisraeli (eds.), Contesting Inter-Religious Conversion in the Medieval World. Nueva York: Routledge, pp. 24-38.

Thompson, Stith (1955-1958). Motif-Index of Folk-Literature, a Classification of Narrative Elements in Folktales, Ballads, Myths, Fables, Mediaeval Romances, Exempla, Fabliaux, Jest-Books and Local Legends. Bloomington: Indiana University Press, 2. ${ }^{a}$ ed. revisada, 6 vols.

Torres Fontes, Juan (1977). «El señorío de Alguazas en la Edad Media», Murgetana. 49, pp. 81-114.

Torres Fontes, Juan (1985). «Murcia medieval. Testimonio documental», Murgetana. 68, pp. 79-130.

Truchado, Francisco. Véase: Straparola, Giovanfrancesco (2016). Honesto y agradable entretenimiento de damas y galanes, trad. Francisco Truchado, Leonardo Coppola (ed.). Madrid: SIAL.

Vega, Lope de (1968). La Dorotea, Edwin S. Morby (ed.). Berkeley y Los Ángeles: University of California Press, 2 . $^{\text {a }}$ ed. revisada.

Recibido: 8 de marzo de 2018

Aceptado: 10 de mayo de 2018 